\title{
Elaboració d'una \\ rúbrica per avaluar la \\ competència digital \\ del docent
}

\section{José Luis Lázaro Cantabrana ${ }^{\mathrm{a}}$ Mercè Gisbert Cervera ${ }^{\mathrm{b}}$}

Rebut: 15/05/2015 Acceptat: 28/06/2015

\begin{abstract}
Resum
La progressiva digitalització dels diferents àmbits de desenvolupament dels ciutadans del S. XXI planteja unes noves demandes socials i una adaptació del sistema educatiu a aquestes.

El desenvolupament de les competències clau dels individus, en concret de la competència digital $(C D)$, és fonamental per poder viure i participar en la societat actual, una societat digital. El desenvolupament de la CD dels ciutadans implica una transformació en quant al què, al com s'aprèn i al com s'ensenya als centres educatius. Els docents necessiten unes destreses i habilitats, cada vegada més complexes, relacionades amb la incorporació de les tecnologies digitals en el processos d'ensenyament-aprenentatge $(E-A)$, aquestes formen part de la competència digital docent (CDD).
\end{abstract}

La CDD és una competència per a la que els docents s'han de formar, tant en un moment inicial com de forma permanent. A la necessitat de formar-se en CDD sorgeix la necessitat d'avaluar el desenvolupament de la mateixa.

Per a poder dur a terme un procés d'avaluació de la CDD s'ha dissenyat i validat una rúbrica que permeti recollir les dimensions de la competència i els seus nivells de desenvolupament.Palabras clave: Enseñanza de la traducción, iniciación a la traducción, formación por competencias, enfoque por tareas, evaluación, semipresencialidad.

Paraules clau: Competència digital docent, rúbrica, avaluació, formació

\footnotetext{
a Universitat Rovira i Virgili

b Universitat Rovira i Virgili
} 


\section{Development of a rubric to assess the digital competence of teachers}

\section{Abstract}

The progressive digitalization of various areas of development of the citizens of the XXI century entails new social demands and adapting the education system to them.

The development of key competencies of individuals, in particular the digital competence, it is essential to live and participate in society, digital society. The development of the digital competence citizens implies a transformation of what, of how to learn and how to teach in schools. Teachers need some skills and increasingly complex related to the incorporation of digital technologies in the teaching-learning process, this skills are part of the digital teaching competence.

The digital teaching competence is a competence for which teachers should be trains an initial moment and permanent. The need to training in digital teaching competence implies the need to assess the development of it.

In order to carry out an evaluation process of the digital teaching competence has been designed and validated a rubric that allows inspect dimensions of the competence and their levels of development.

Keywords: Digital competence teacher, rubric, evaluation, training

\section{Introducción}

El desenvolupament tecnològic ha produït una expansió i distribució del coneixement sense precedents. Aquest coneixement viatja per la xarxa en forma de dades generant noves formes d'aprendre, de comunicar-se i de relacionar-se que condicionen la forma en què vivim i participem de la societat (Castells, 2000 i 2002; Krugman, 2012; Comisión Europea, 2013a; Unión Europea, 2014). Aquest fet produeix efectes d'igualtat i desigualtat de manera simultània: efectes d'inclusió i d'exclusió social relacionats amb l'accés o no a la tecnologia (Lázaro et al. 2015).

Els ciutadans del S. XXI necessiten desenvolupar una sèrie de competències clau que els permetin participar, des del punt de vista de la inclusió, i desenvolupar-se, des del punt de vista personal i professional, en una "societat digital" (Unión Europea, 2006; Unesco, 2009; Comisión Europea, 2013a; ). La Unión Europea (2006) recull 8 competències clau per l'aprenentatge entre les que es troba la CD. Així mateix, el domini de les tecnologies digitals es considera una capacitat bàsica fonamental, a l'alçada de la llengua, la lectura, l'escriptura i el càlcul que ha de permetre als ciutadans desenvolupar les competències fonamentals per a viure en societat.

Des del punt de vista del sistema educatiu cal disposar de docents competents per poder donar resposta a aquestes noves demandes socials i formar en competències bàsiques els ciutadans actuals (Generalitat de Catalunya, 2009). 
Entenem l'educació i la cultura com el motor per al desenvolupament de qualsevol país (Comisión Europea, 2012b). Les institucions educatives han sofert una transformació a partir de la digitalització constant dels seus àmbits. La tecnologia digital té un gran potencial per transformar els processos formatius (Slavich \& Zimbarno, 2012) proporcionant als nous aprenents noves estratègies, espais, models i oportunitats per aprendre (Katic, 2008; Gisbert \& Esteve, 2011; Gisbert \& Johnson, 2015).

\section{El perfil del docent en una societat}

Les noves generacions d'aprenents, els "aprenents digitals" (Prensky, 2001; Oblinger \& Oblinger, 2005; Pedró, 2009; Gisbert \& Esteve, 2011; Esteve, 2015), són persones que han crescuts amb la tecnologia digital immersa a la seva vida quotidiana, que fan un ús natural d'aquesta i que posseeixen un nivell d'habilitats tecnològiques més alt que les generacions anteriors.

Des del punt de vista del sistema educatiu, la formació en competències bàsiques d'aquests alumnes, sent la CD una d'elles, suposa la necessitat de disposar de docents que tinguin un nivell de $C D$ que els permeti utilitzar la tecnologia amb eficàcia en les seves activitats amb els estudiants, als centres educatius i amb la comunitat educativa (Comisión Europea, 2013b; OECD, 2012; Sánchez-Antolín et al., 2014). Estem parlant del concepte de CDD.

La importància de formar els docents actuals en CDD és un tema àmpliament tractat a la literatura i a les recomanacions d'organismes internacionals (Almås \& Krumsvik, 2007; Tejada, 2009; Wilson et al. 2011, Gisbert et al. 2015; Comisión Europea, 2012a i 2013c; Unesco, 2008, 2011 i 2013). Hi ha diversos referents internacionals que hem tingut en compte al nostre treball (EPICT, 2006; ISTE, 2008; Unesco, 2008; Enlaces, 2011; Comisión Europea, 2013c) que presenten propostes d'estandardització mitjançant les quals organitzen la CDD en coneixements i habilitats necessàries per al professorat.

Amb la necessitat de formar en CDD el professorat va associat la necessitat d'avaluarla. A més d'identificar quins són els components de la CDD esdevé necessari conèixer quin són els diferents nivells de desenvolupament de la mateixa i disposar d'un instrument que ens permeti fer una gradació en l'aprenentatge, orientar els docents sobre la seva situació competencial i cap a on orientar-la per a seguir avançant.

En aquest sentit presentem, en el següent apartat, una rúbrica que ha de servir de guia per avaluar la CDD. 


\section{Elaboració de la rúbrica per l'avaluació de la competència digital docent (CDD).}

\subsection{Disseny de la rúbrica}

El treball de disseny d'una rúbrica per avaluar la CDD sorgeix de la necessitat vinculada al desenvolupament de dos treballs que s'estan duent a terme pel grup de recerca ARGET de la Universitat Rovira i Virgili de Tarragona i que formen part de dos projectes: ARMIF 2014» (Ref. 2014 ARMIF 00039) de la Generalitat de Cataluña i el de la convocatòria d'ajuts a projectes d' I+D del Ministerio de Economía y Competitividad del Gobierno de España (Ref. EDU2013-42223-P) .

Pel disseny de la rúbrica hem seguit el procés utilitzat per Larraz (2013) a partir del treball de Mertler (2001). Hem adoptat un procés que es concreta de la següent manera:

a) Documentació i selecció de referents teòrics.

b) Identificació de les dimensions de la CDD.

c) Identificació dels àmbits on es desenvolupa la CDD.

d) Concreció teòrica dels nivells de desenvolupament.

e) Identificació dels indicadors de cada dimensió.

f) Redacció dels nivells de desenvolupament dels indicadors: els més baixos i els més alts.

g) Redacció dels nivells de desenvolupament dels indicadors: nivells intermedis.

h) Revisió de la rúbrica.

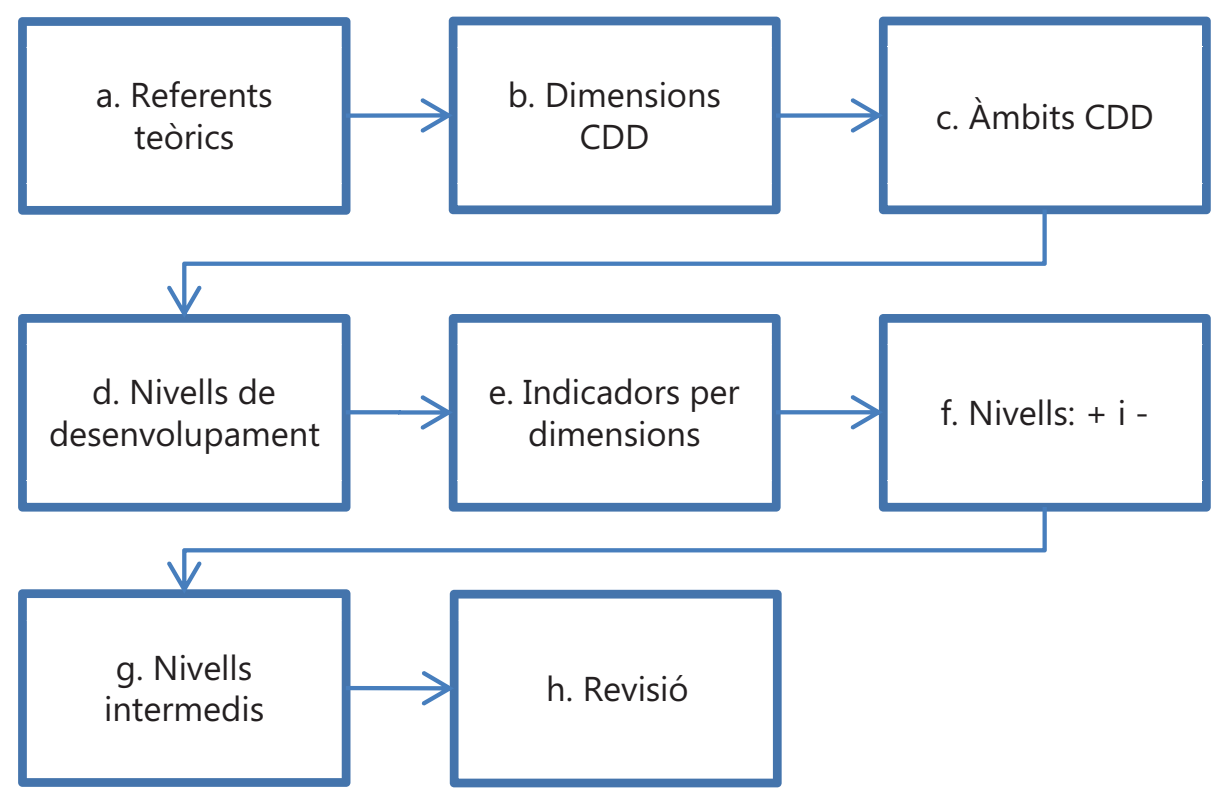

Figura 1. Model del procés de disseny de la rúbrica. Font: elaboració pròpia. 
a) A continuació presentem en una taula quins són els referents emprats per elaborar cada element de la rúbrica.

\begin{tabular}{|c|c|}
\hline Referents & Elements de la rúbrica \\
\hline Churches (2007) & Nivells de de desenvolupament de la CDD \\
\hline $\begin{array}{l}\text { Unesco (2008 i 2013) } \\
\text { Comisión Europea } \\
(2013 c)\end{array}$ & Dimensions, àmbits i Indicadors de la CDD \\
\hline ISTE (2008) & $\begin{array}{l}\text { Dimensions, àmbits indicadors i nivells de } \\
\text { desenvolupament de la CDD }\end{array}$ \\
\hline Enlaces (2011) & Dimensions i indicadors de la CDD \\
\hline Larraz (2013) & $\begin{array}{l}\text { Dimensions, indicadors i nivells de desenvolupament de la } \\
\text { CDD }\end{array}$ \\
\hline $\begin{array}{l}\text { Fraser, J., Atkins, L., \& } \\
\text { Richard, H. (2013) }\end{array}$ & Dimensions de la CDD \\
\hline $\begin{array}{l}\text { Generalitat de } \\
\text { Catalunya }(2013 b)\end{array}$ & Àmbits de la CDD \\
\hline
\end{tabular}

Taula 1. Referents per a l'elaboració de la rúbrica de CDD. Font: elaboració pròpia.

b) Vam establir quines havien de ser les dimensions, enteses com allò inherent a la professió docent, que s'havien de contemplar a la rúbrica i a partir de les quals s'agruparien els indicadors.

\section{Es van establir $\mathbf{4}$ dimensions:}

1. Didàctica, curricular i metodològica.

2. Planificació, organització i gestió d'espais i recursos tecnològics digitals.

3. Relacional, ètica i seguretat.

4. Personal i professional.

c) Vam contemplar incloure a la rúbrica uns àmbits, entesos com la situació professional amb el conjunt de funcions en les que un docent ha de ser competent, aquests han de servir com a referent per a saber on recollir evidències per l'avaluació o per l'acreditació.

Es van establir 4 àmbits $i$ es van redactar $\mathrm{i}$ incloure a l'instrument exemples de competències derivades d'accions docents de cada un d'ells: 
- Àmbit aula: Els docents utilitzen dispositius digitals a l'aula, dissenyen i programen activitats d'E-A amb les tecnologies digitals, gestionen l'aula, fan el seguiment i avaluació dels alumnes amb les tecnologies digitals i programen I'E-A de la CD dels alumnes.

- Àmbit centre educatiu: Els docents utilitzen i preserven les infraestructures i les tecnologies digitals del centre, respecten la identitat digital de la institució, realitzen el seguiment i coordinació pedagògica amb els recursos digitals institucionals i incorpora com a seves les estratègies formatives en l'àmbit tecnològic del centre.

- Àmbit comunitat educativa i entorn: Els docents utilitzen i organitzen els recursos que el centre disposa per a la participació social.

- Àmbit desenvolupament professional: Els docents configuren el seu entorn personal d'aprenentatge (EPA), treballen en xarxa, gestionen la seva identitat digital, es formen permanentment, modelen i lideren l'ús de les tecnologies digitals.

d) Es van contemplar i definir 4 nivells de desenvolupament a partir de la premissa que l'instrument havia de servir com a eina que pogués recollir el desenvolupament de CDD en termes de màxims, des d'un nivell inicial fins a un nivell transformador.

A la rúbrica és va incloure la definició de cada nivell de desenvolupament de la competència i un exemple de cada un d'ells per facilitar la seva comprensió als avaluadors:

1. Nivell principiant: utilitza les tecnologies digitals com a facilitadores i elements de millora del procés d'E-A.

Exemple: docent novell o en procés de formació inicial que incorpora les tecnologies digitals en els processos d'E-A.

2. Nivell mitjà: utilitza les tecnologies digitals per a la millora del procés d'E-A de forma flexible i adaptada al context educatiu.

Exemple: docent amb dos o més anys d'experiència que utilitza i gestiona els recursos i espais tecnològics de l'aula i del centre adaptant-los a les necessitats.

3. Nivell expert: utilitza les tecnologies digitals de forma eficient per millorar els resultats acadèmics dels alumnes, la seva acció docent $\mathrm{i}$ la qualitat del centre educatiu.

Exemple: docent que serveix de model o líder al centre educatiu en l'ús de les tecnologies digitals. 
4. Nivell transformador: utilitza les tecnologies digitals, investiga sobre el seu ús per millorar els processos d'E-A i exporta les seves conclusions per tal de donar resposta a les necessitats del sistema educatiu.

Exemple: docent que actua de forma constant i compromesa analitzant de forma reflexiva i sistemàtica la seva pràctica, descobrint nous usos d'aplicació de la tecnologia a l'educació, compartint els resultats de les seves investigacions en les xarxes professionals amb la intenció de generar coneixement.

e) De cada dimensió, es van redactar els conceptes claus que havien de servir per definir posteriorment cada indicador.

f) A partir dels conceptes clau, es va redactar el nivell més baix (principiant) i més alt (transformador) de cada indicador.

g) A partir dels nivells 1 i 4 es van redactar els nivells intermedis (mitjà-expert) per tal de definir la gradació intermèdia de cada indicador.

h) La revisió orientada a la validació de la rúbrica es va realitzar a partir del treball d'un grup de discussió i d'un judici d'experts.

A continuació explicarem com vam dur a terme el procés de validació de l'instrument.

\subsection{Validació de la rúbrica mitjançant un grup de discussió.}

La primera validació de la rúbrica de CDD és va dur a terme mitjançant la creació d'un grup de discussió.

El grup de discussió com a tècnica qualitativa d'investigació social (Krueger, 1991) on es planteja una conversa planejada i dirigida per un moderador expert. Tots els participants exposen les seves idees i comentaris, influenciant uns als altres, al voltant del tema de la discussió i cercant la convergència de les seves opinions (Delgado \& Gutiérrez, 1999).

La missió del grup és la revisió del procés, de la metodologia emprada i la revisió de tots els documents generats. D'aquesta manera el grup de discussió actua com a primer nivell de validació de l'instrument.

El grup de discussió utilitza el model de "recerca per al disseny" (Van den Akker et al. 2006), els seus membres eren diferents en cada fase $i$ es van reunir fent diferents iteracions del procés fins aconseguir una versió final del document. 


\subsubsection{Membres del grup de discussió.}

El grup de discussió estava format per 10 experts en tecnologia educativa, amb perfils diversos, que podien aportar la seva perspectiva i experiència:

- 8 professors i membres en actiu de grups de recerca relacionats amb la tecnologia educativa de diferents universitats catalanes,

- 1 docent en actiu i coordinadors TIC d'un centre d'educació infantil i primària i

- 1 director d'un centre d'educació secundària, doctor en tecnologia educativa.

\subsubsection{Planificació del grup de discussió.}

El grup es reuneix en tres ocasions per tal de revisar la rúbrica en diferents moments de la seva elaboració que coincideixen amb el procés de disseny que s'ha explicat anteriorment i que recollim a la següent taula:

\begin{tabular}{|c|c|}
\hline Fases de la validació & Accions \\
\hline $\begin{array}{l}\text { 1. Anàlisi del } \\
\text { procediment }\end{array}$ & $\begin{array}{l}\text { - } \quad \text { Revisió de referents teòrics. } \\
\text { - } \quad \text { Concreció de les dimensions de la CDD. } \\
\text { - } \quad \text { Concreció dels àmbits on es desenvolupa la CDD. } \\
\text { - } \quad \text { Concreció teòrica dels nivells de } \\
\text { desenvolupament. }\end{array}$ \\
\hline $\begin{array}{l}\text { 2. Anàlisi del contingut } \\
\text { de l'instrument }\end{array}$ & $\begin{array}{l}\text { - Definició dels indicadors de cada dimensió. } \\
\text { - Definició dels nivells de desenvolupament dels } \\
\text { indicadors. }\end{array}$ \\
\hline $\begin{array}{l}\text { 3. Revisió global de } \\
\text { l'instrument }\end{array}$ & $\begin{array}{l}\text { - Revisió dels elements i format final de l'instrument } \\
\text { d'avaluació. }\end{array}$ \\
\hline
\end{tabular}

Taula 2. Fases del procés validació de la rúbrica: grup de discussió. Font: elaboració pròpia.

A partir d'aquest procés es van incorporar a la rúbrica les aportacions dels diferents membres fins que es va tenir una versió de la mateixa que ens va permetre sotmetrela a judici d'experts.

\subsection{Validació de la rúbrica mitjançant judici d'experts.}

El procés de validació de l'instrument ha estat complex donat l'abast del mateix i el fet de què pretenguéssim que sigui aplicable en diferents moments professionals (formació inicial del docent $\mathrm{i}$ docents en actiu) i en diferents contextos i nivells educatius (universitat i centres educatius d'educació infantil, primària i secundària). Per tot això hem considerat necessari copsar l'opinió i visió de professionals experts en actiu que aportessin millores a la rúbrica durant aquesta fase de validació. 


\subsubsection{Membres del grup d'experts}

Aquest grup ha estat seleccionat tenint en compte que estesin tots els contextos, nivells educatius, càrrecs de gestió als centres educatius i a les administracions representats.

Els professionals han estat 15 persones membres en actiu de

\begin{tabular}{|lll|}
\hline Nombre & \multicolumn{1}{c|}{ Perfil } & \multicolumn{1}{c|}{ Institució } \\
\hline $\mathbf{8}$ & Professor+membre de grup de recerca & Universitats catalanes \\
\hline $\mathbf{1}$ & Professor+membre de grup de recerca & Universitat estat espanyol \\
\hline $\mathbf{1}$ & Professor+membre de grup de recerca & Universitat europea \\
\hline $\mathbf{2}$ & Docent en actiu & Administració educativa \\
\hline $\mathbf{1}$ & Inspector & Administració educativa \\
\hline $\mathbf{1}$ & Membre àrea TIC & Administració educativa \\
\hline $\mathbf{1}$ & Membre Consell Escolar de Catalunya & Administració educativa \\
\hline
\end{tabular}

\subsubsection{Validesa de contingut de la rúbrica}

Per tal de validar el contingut de la rúbrica, es demana als experts que valorin la representativitat dels ítems en relació amb el contingut a mesurar (Larraz, 2013).

Per una banda els experts valoren amb una escala d'1 a 4 el grau de pertinença i claredat dels indicadors:

1. Pertinença: grau d'adequació i conveniència dels indicadors.

2. Claredat: grau de comprensió dels indicadors.

Per altra banda es demana als experts que valorin obertament i que realitzin les aportacions necessàries sobre:

3. La gradació dels indicadors de la rúbrica en funció dels nivells definits.

4. La concreció dels indicadors en funció de les dimensions i àmbits de la CDD.

A partir de les dades aportades pels experts, s'analitzen de forma quantitativa i qualitativa, es realitzen noves modificacions de la rúbrica i s'obté una nova versió d'aquest instrument que presentem de forma completa a continuació.

\section{Conclusions}

Des del punt de vista de la formació en CD de docents, tan inicial com permanent, esdevé necessari disposar d'instruments que ens permetin recollir dades reals, basades en evidències, dels diferents nivells de desenvolupament de la competència. Els instruments d'avaluació de competències basats en l'autopercepció de l'avaluat no 
ofereixen un resultat ajustats a la situació real, tendeixen a reflectir un nivell més alt de competència (Esteve, 2015).

La creació de la rúbrica com a eina per a l'avaluació de la CDD, vinculat al desenvolupament de processos de recerca, ens ha de permetre recollir el resultat d'avaluació a partir d'evidències i determinar el nivell real de desenvolupament de la competència i conèixer cap a on avançar per assolir un nivell superior.

L'avaluació en CDD del professorat en actiu ha de servir com element dins del procés d'anàlisi de millora de la qualitat dels propis docents i dels centres educatius. Aquest procés ha de permetre planificar la formació permanent en l'àmbit de la tecnologia digital com a element d'innovació, canvi i millora.

Com a línies futures de treball, proposem la incorporació de la CD en la formació inicial dels docents. Des del punt de vista de les universitats, aquest fet suposa una revisió dels plans d'estudi dels graus d'educació de manera que contemplin la CD com a competència nuclear en el currículum de l'alumnat.

Des del punt de vista de l'acreditació del la CDD caldrà dissenyar processos interinstitucionals, com el que s'està desenvolupant per la Generalitat de Catalunya (2015) amb col-laboració de totes les universitats catalanes, per a definir i acreditar la CD dels docents. D'aquesta manera les institucions responsables en l'acreditació dels docents (inicial i permanent) defineixen els processos i els seus elements de forma conjunta. 
Els indicadors s'han agrupat tenint en compte $\mathbf{4}$ dimensions enteses com allò inherent a la professió docent. Alhora, s'han definit $\mathbf{4}$ àmbits entesos com la situació professional amb el conjunt de funcions en les que un docent ha de ser competent, aquests han de servir com a referent per a saber on recollir evidències per l'avaluació o per l'acreditació.

\begin{tabular}{|l|l|l|}
\hline Dimensions & Àmbits \\
\hline 1. & Didàctica, curricular i metodològica & $1 . \quad$ Aula (entès com a "escenari" o context on actua el docent, no com a espai físic) \\
\hline 2. & Planificació, organització i gestió d'espais i recursos tecnològics digitals & $2 . \quad$ Centre educatiu \\
\hline 3. & Relacional, ètica i seguretat & $3 . \quad$ Comunitat educativa i entorn \\
\hline 4. & Personal i professional & $4 . \quad$ Desenvolupament professional \\
\hline
\end{tabular}

\section{Exemples de competències pròpies de cada àmbit}

- Àmbit aula: Els docents utilitzen dispositius digitals a l'aula, dissenyen i programen activitats d'E-A amb les tecnologies digitals, gestionen l'aula, fan el seguiment $i$ avaluació dels alumnes amb les tecnologies digitals i programen l'E-A de la CD dels alumnes.

- Àmbit centre educatiu: Els docents utilitzen i preserven les infraestructures i les tecnologies digitals del centre, respecten la identitat digital de la institució, realitzen el seguiment i coordinació pedagògica amb els recursos digitals institucionals i incorpora com a seves les estratègies formatives en l'àmbit tecnològic del centre.

- Àmbit comunitat educativa i entorn: Els docents utilitzen i organitzen els recursos que el centre disposa per a la participació social.

- Àmbit desenvolupament professional: Els docents configuren el seu entorn personal d'aprenentatge (EPA), treballen en xarxa, gestionen la seva identitat digital, es formen permanentment, modelen i lideren l'ús de les tecnologies digitals.

S'han definit 4 nivells de desenvolupament de la competència

1. Principiant: utilitza les tecnologies digitals com a facilitadores i elements de millora del procés d'E-A.

Exemple: docent novell o en procés de formació inicial que incorpora les tecnologies digitals en els processos d'E-A

2. Mitjà: utilitza les tecnologies digitals per a la millora del procés d'E-A de forma flexible i adaptada al context educatiu.

Exemple: docent amb dos o més anys d'experiència que utilitza i gestiona els recursos i espais tecnològics de l'aula i del centre adaptant-los a les necessitats.

3. Expert: utilitza les tecnologies digitals de forma eficient per millorar els resultats acadèmics dels alumnes, la seva acció docent i la qualitat del centre educatiu Exemple: docent que serveix de model o líder al centre educatiu en l'ús de les tecnologies digitals.

4. Transformador: utilitza les tecnologies digitals, investiga sobre el seu ús per millorar els processos d'E-A i exporta les seves conclusions per tal de donar resposta a les necessitats del sistema educatiu.

Exemple: docent que actua de forma constant i compromesa analitzant de forma reflexiva i sistemàtica la seva pràctica, descobrint nous usos d'aplicació de la tecnologia a

l'educació, compartint els resultats de les seves investigacions en les xarxes professionals amb la intenció de generar coneixement.

Referents i fonts d'informació per a l'elaboració de la rúbrica: ISTE (2008), Unesco (2008), Enlaces (2011), Larraz (2013), Fraser, J., Atkins, L., \& Richard, H. (2013), Comissió

Europea (2013c) IPTS 
DIMENSIÓ 1. Didàctica, curricular i metodològica

\begin{tabular}{|c|c|c|c|c|c|}
\hline Àmbits & $\begin{array}{l}\text { Conceptes clau } \\
\text { per a la definició } \\
\text { dels indicadors }\end{array}$ & Nivell 1. Principiant & Nivell 2. Mitjà & Nivell 3. Expert & Nivell 4. Transformador \\
\hline Aula & $\begin{array}{l}\text { 1. Tractament de } \\
\text { la informació i } \\
\text { creació de } \\
\text { coneixement }\end{array}$ & $\begin{array}{l}\text { Ensenya a realitzar cerques } \\
\text { d'informació accedint a } \\
\text { diferents fonts de diversa } \\
\text { tipologia. }\end{array}$ & $\begin{array}{l}\text { Ensenya a utilitzar fonts } \\
\text { d'informació de diferent } \\
\text { tipologia atenent a criteris de } \\
\text { qualitat, veracitat i pertinença. }\end{array}$ & $\begin{array}{l}\text { Ensenya a classificar, ordenar i } \\
\text { seleccionar la informació des de } \\
\text { diferents fonts aplicant criteris de } \\
\text { qualitat, veracitat i pertinença. }\end{array}$ & $\begin{array}{l}\text { Ensenya a crear i transformar la informació, que } \\
\text { prèviament s'ha emmagatzemat i recuperat, } \\
\text { seguint un sistema que el permeti fer un ús } \\
\text { compartit. }\end{array}$ \\
\hline Aula & $\begin{array}{l}\text { 2. Les tecnologies } \\
\text { digitals com a } \\
\text { facilitadores de } \\
\text { 'aprenentatge }\end{array}$ & $\begin{array}{l}\text { Utilitza programari de suport } \\
\text { a l'aula per dur a terme } \\
\text { activitats d'E-A. }\end{array}$ & $\begin{array}{l}\text { Du a terme activitats amb els } \\
\text { alumnes que impliquen la } \\
\text { resolució de problemes de forma } \\
\text { col·laborativa mitjançant l'ús de } \\
\text { recursos tecnològics digitals. }\end{array}$ & \begin{tabular}{|l|} 
Planteja activitats amb els alumnes \\
que impliquen: I'anàlisi d'un \\
problema en grup, la proposta de \\
solucions alternatives, la negociació \\
dels resultats i la seva publicació fent \\
ús de recursos tecnològics digitals. \\
\end{tabular} & $\begin{array}{l}\text { Estimula l'aprenentatge autònom i el treball } \\
\text { col-laboratiu mitjançant la transformació i } \\
\text { creació de coneixements a partir de situacions } \\
\text { que s'hagin de resoldre fent ús de recursos } \\
\text { tecnològics digitals. }\end{array}$ \\
\hline Aula & $\begin{array}{l}\text { 3. Atenció a la } \\
\text { diversitat }\end{array}$ & $\begin{array}{l}\text { Utilitza les tecnologies digitals } \\
\text { per augmentar la motivació i } \\
\text { facilitar l'aprenentatge amb } \\
\text { alumnes amb necessitats } \\
\text { específiques de suport } \\
\text { educatiu (NESE). } \\
\end{array}$ & $\begin{array}{l}\text { Utilitza les tecnologies digitals } \\
\text { per donar resposta a les NESE, } \\
\text { com a element d'accés al } \\
\text { currículum tenint en compte la } \\
\text { inclusió digital de l'alumnat. }\end{array}$ & $\begin{array}{l}\text { Elabora materials i recursos } \\
\text { personalitzats per atendre les NESE } \\
\text { de l'alumnat i per compensar les } \\
\text { desigualtats d'accés a la tecnologia. }\end{array}$ & $\begin{array}{l}\text { Comparteix amb altres professionals els } \\
\text { recursos materials didàctics digitals per atendre } \\
\text { les NESE tenint en compte el concepte de } \\
\text { "disseny per a tothom" i les normes } \\
\text { d'accessibilitat. }\end{array}$ \\
\hline Aula & $\begin{array}{l}\text { 4. La CD dels } \\
\text { alumnes a la } \\
\text { planificació docent }\end{array}$ & $\begin{array}{l}\text { Dissenya activitats d'E-A on } \\
\text { contempla l'ús de les } \\
\text { tecnologies digitals. }\end{array}$ & $\begin{array}{l}\text { Recull a la planificació didàctica } \\
\text { la cerca, tractament, } \\
\text { emmagatzematge i difusió de la } \\
\text { informació digital en diferents } \\
\text { formats. }\end{array}$ & $\begin{array}{l}\text { Pauta i recull a la planificació } \\
\text { didàctica l'ús i el bon ús de les } \\
\text { tecnologies digitals orientades a la } \\
\text { publicació d'informació i el treball } \\
\text { col·laboratiu. }\end{array}$ & $\begin{array}{l}\text { Dissenya activitats competencialment riques } \\
\text { (funcionals, transversals i orientades a } \\
\text { l'autonomia) que impliquin habilitats } \\
\text { complexes: resoldre problemes i situacions } \\
\text { reals, interpretar, comunicar, ..., on s'hagin de } \\
\text { fer un "bon ús" de les tecnologies digitals. }\end{array}$ \\
\hline $\begin{array}{l}\text { Centre } \\
\text { educatiu }\end{array}$ & $\begin{array}{l}\text { 5. Línia } \\
\text { metodològica de } \\
\text { centre }\end{array}$ & $\begin{array}{l}\text { Coneix les orientacions del } \\
\text { centre per a la incorporació } \\
\text { de les tecnologies digitals a } \\
\text { l'aula i les té en compte a les } \\
\text { seves programacions } \\
\text { didàctiques. }\end{array}$ & $\begin{array}{l}\text { Programa i desenvolupa } \\
\text { activitats orientades al } \\
\text { desenvolupament de la } \\
\text { competència digital en funció de } \\
\text { les orientacions metodològiques } \\
\text { i dels recursos dels que disposa. }\end{array}$ & $\begin{array}{l}\text { Incorpora la CD a activitats } \\
\text { significatives (funcionals, transversals } \\
\text { i que afavoreixen l'autonomia) que } \\
\text { impliquen l'ús de les tecnologies } \\
\text { digitals per construir i compartir el } \\
\text { coneixement. } \\
\end{array}$ & $\begin{array}{l}\text { Proposa noves estratègies metodològiques } \\
\text { innovadores i serveix de model docent per al } \\
\text { treball de la CD. }\end{array}$ \\
\hline $\begin{array}{l}\text { Aula } \\
\text { Centre } \\
\text { educatiu }\end{array}$ & $\begin{array}{l}\text { 6. Avaluació, } \\
\text { tutoria i seguiment } \\
\text { dels alumnes }\end{array}$ & $\begin{array}{l}\text { Utilitza recursos digitals per a } \\
\text { la tutoria i seguiment de } \\
\text { l'alumnat (reunions, } \\
\text { assistència, avaluació, } \\
\text { expedient, ...) }\end{array}$ & $\begin{array}{l}\text { Utilitza recursos digitals } \\
\text { compartits per realitzar } \\
\text { l'avaluació i el seguiment dels } \\
\text { alumnes junt amb els altres } \\
\text { professionals del centre. }\end{array}$ & $\begin{array}{l}\text { Utilitza un recurs digital per } \\
\text { compartir l'avaluació i el seguiment } \\
\text { dels alumnes amb les famílies. }\end{array}$ & $\begin{array}{l}\text { Gestiona i utilitza recursos digitals (entorns, } \\
\text { portafolis digitals, ...) per fer el seguiment } \\
\text { escolar i l'avaluació dels alumnes a nivell de } \\
\text { centre i d'administració educativa. }\end{array}$ \\
\hline
\end{tabular}




\begin{tabular}{|c|c|c|c|c|c|}
\hline Àmbits & $\begin{array}{l}\text { Conceptes clau } \\
\text { per a la } \\
\text { definició dels } \\
\text { indicadors }\end{array}$ & $\begin{array}{l}\text { Nivell } 1 . \\
\text { Principiant }\end{array}$ & Nivell 2. Mitjà & Nivell 3. Expert & Nivell 4. Transformador \\
\hline $\begin{array}{l}\text { Aula } \\
\text { Centre educatiu }\end{array}$ & $\begin{array}{ll}\text { 1. } & \text { Ambients } \\
\text { d'aprenentatge }\end{array}$ & $\begin{array}{l}\text { Utilitza les tecnologies } \\
\text { digitals d'aula: PDI, } \\
\text { dispositius fixes i } \\
\text { mòbils, ..., en funció de } \\
\text { cada situació d'E-A. }\end{array}$ & $\begin{array}{l}\text { Adequa les activitats } \\
\text { d'E-A als espais i a les } \\
\text { tecnologies digitals } \\
\text { de centre } \\
\text { disponibles. }\end{array}$ & $\begin{array}{l}\text { Modifica els espais d'E-A amb } \\
\text { tecnologies digitals per millorar- } \\
\text { los i optimitzar la infraestructura } \\
\text { disponible a partir d'uns criteris } \\
\text { compartits. }\end{array}$ & $\begin{array}{l}\text { Organitza i gestiona els espais del centre } \\
\text { atenent a criteris d'optimització i dotació } \\
\text { de tecnologies digitals en funció d'una } \\
\text { anàlisi prèvia de necessitats. }\end{array}$ \\
\hline Centre educatiu & $\begin{array}{l}\text { 2. Espais amb } \\
\text { tecnologies digitals } \\
\text { de centre }\end{array}$ & $\begin{array}{l}\text { Identifica els espais } \\
\text { amb tecnologies } \\
\text { digitals del centre i } \\
\text { coneix el seu } \\
\text { funcionament. }\end{array}$ & $\begin{array}{l}\text { Utilitza } \\
\text { responsablement } \\
\text { diferents espais i } \\
\text { tecnologies digitals } \\
\text { del centre amb els } \\
\text { alumnes. }\end{array}$ & $\begin{array}{l}\text { Incorpora les innovacions en l'ús } \\
\text { dels recursos tecnològics digitals } \\
\text { i espais virtuals a les seves } \\
\text { activitats diàries amb els } \\
\text { alumnes. }\end{array}$ & $\begin{array}{l}\text { Gestiona espais amb tecnologies digitals } \\
\text { en funció dels resultats obtinguts en } \\
\text { l'anàlisi de la seva pràctica diària. }\end{array}$ \\
\hline Aula & $\begin{array}{l}\text { 3. Gestió de } \\
\text { tecnologies digitals } \\
\text { i programari }\end{array}$ & $\begin{array}{l}\text { Avalua i selecciona els } \\
\text { recursos i les eines } \\
\text { existents per al treball } \\
\text { a l'aula. }\end{array}$ & $\begin{array}{l}\text { Selecciona i utilitza } \\
\text { els recursos i eines } \\
\text { més adients per a } \\
\text { diferents situacions } \\
\text { d'E-A. }\end{array}$ & $\begin{array}{l}\text { Combina l'ús de diferents } \\
\text { tecnologies digitals en funció de } \\
\text { la seva potencialitat analitzant de } \\
\text { forma reflexiva el rendiment dels } \\
\text { alumnes a partir de la seva } \\
\text { utilització. }\end{array}$ & $\begin{array}{l}\text { Investiga situacions d'E-A basades en la } \\
\text { utilització des les tecnologies digitals i } \\
\text { innova a partir dels resultats obtinguts. }\end{array}$ \\
\hline Centre educatiu & $\begin{array}{l}\text { 4. Infraestructure } \\
\text { s tecnològiques } \\
\text { digitals }\end{array}$ & $\begin{array}{l}\text { Fa un ús responsable } \\
\text { de les tecnologies } \\
\text { digitals i utilitza un } \\
\text { protocol per resoldre } \\
\text { incidències. }\end{array}$ & $\begin{array}{l}\text { Adopta a la seva } \\
\text { pràctica les } \\
\text { innovacions vers l'ús } \\
\text { responsable i } \\
\text { actualitzat dels } \\
\text { recursos. }\end{array}$ & $\begin{array}{l}\text { Resol incidències de manera } \\
\text { autònoma de l'equipament d'ús } \\
\text { personal i de l'aula i fa propostes } \\
\text { de millora per a la seva } \\
\text { utilització. }\end{array}$ & $\begin{array}{l}\text { Gestiona l'ús de les tecnologies digitals i } \\
\text { promou el manteniment i bon ús de la } \\
\text { infraestructura tecnològica del centre. }\end{array}$ \\
\hline Centre educatiu & $\begin{array}{l}\text { 5. Projectes } \\
\text { d'incorporació de } \\
\text { les tecnologies } \\
\text { digitals }\end{array}$ & $\begin{array}{l}\text { Segueix les directrius } \\
\text { acordades a nivell de } \\
\text { centre sobre l'ús de les } \\
\text { tecnologies digitals en } \\
\text { la docència. }\end{array}$ & $\begin{array}{l}\text { Forma part activa } \\
\text { dels equips de centre } \\
\mathrm{i} \text { aporta la seva } \\
\text { experiència i } \\
\text { coneixements al } \\
\text { voltant de les } \\
\text { tecnologies digitals. }\end{array}$ & $\begin{array}{l}\text { Lidera un equip de treball del } \\
\text { centre fent-se càrrec de } \\
\text { gestionar la utilització de les } \\
\text { tecnologies digitals en la pràctica } \\
\text { diària. }\end{array}$ & $\begin{array}{l}\text { Lidera i coordina projectes } \\
\text { interinstitucionals al voltant de la } \\
\text { incorporació de les tecnologies digitals a } \\
\text { la docència. }\end{array}$ \\
\hline
\end{tabular}




\begin{tabular}{|c|c|c|c|c|c|}
\hline Àmbits & $\begin{array}{l}\text { Conceptes clau per a } \\
\text { la definició dels } \\
\text { indicadors }\end{array}$ & Nivell 1. Principiant & Nivell 2. Mitjà & Nivell 3. Expert & Nivell 4. Transformador \\
\hline Aula & 1. Ètica i seguretat & $\begin{array}{l}\text { Respecta els drets d'autor en } \\
\text { els seus materials docents i } \\
\text { utilitza les tecnologies digitals } \\
\text { personals de forma } \\
\text { responsable i segura. }\end{array}$ & $\begin{array}{l}\text { Fa de model en l'ús ètic } \\
\text { de les tecnologies digitals } \\
\text { durant les activitats amb } \\
\text { els alumnes. }\end{array}$ & $\begin{array}{l}\text { Serveix de model per a altres } \\
\text { professionals sobre l'ús } \\
\text { responsable i segur de les } \\
\text { tecnologies digitals. }\end{array}$ & $\begin{array}{l}\text { Planteja directrius sobre l'ús } \\
\text { responsable, ètic i segur de les } \\
\text { tecnologies digitals. }\end{array}$ \\
\hline $\begin{array}{l}\text { Centre educatiu } \\
\text { Comunitat } \\
\text { educativa i entorn }\end{array}$ & 2. Inclusió digital & $\begin{array}{l}\text { Potencia l'accés i ús de les } \\
\text { tecnologies digitals per part } \\
\text { de tot l'alumnat amb la } \\
\text { intenció de compensar les } \\
\text { desigualtats. }\end{array}$ & $\begin{array}{l}\text { Participa en l'organització } \\
\text { de l'atenció a la diversitat } \\
\text { del centre exercint } \\
\text { accions per compensar } \\
\text { les desigualtats a nivell } \\
\text { d'accés i ús de les } \\
\text { tecnologies digitals. }\end{array}$ & $\begin{array}{l}\text { Promou la utilització dels } \\
\text { espais i recursos tecnològics } \\
\text { digitals del centre, per part de } \\
\text { la comunitat educativa, } \\
\text { mitjançant la participació en } \\
\text { accions orientades a la } \\
\text { compensació de les } \\
\text { desigualtats. }\end{array}$ & $\begin{array}{l}\text { Forma els membres de la comunitat } \\
\text { educativa amb accions orientades a } \\
\text { la generalització de l'ús, la gestió i la } \\
\text { difusió de bones pràctiques en l'ús de } \\
\text { les tecnologies digitals. }\end{array}$ \\
\hline Centre educatiu & $\begin{array}{l}\text { 3. Identitat digital del } \\
\text { centre }\end{array}$ & $\begin{array}{l}\text { Coneix la identitat digital del } \\
\text { centre, la necessitat de } \\
\text { respectar els models } \\
\text { documentals i protocols } \\
\text { relatius a la identificació visual } \\
\text { del centre. }\end{array}$ & $\begin{array}{l}\text { Incorpora a les seves } \\
\text { creacions documentals i } \\
\text { espais virtuals la } \\
\text { identificació visual del } \\
\text { centre. }\end{array}$ & $\begin{array}{l}\text { Participa en el manteniment } \\
\text { de la imatge institucional als } \\
\text { espais virtuals del centre. }\end{array}$ & $\begin{array}{l}\text { Gestiona els espais virtuals del centre } \\
\text { vetllant per transmetre una identitat } \\
\text { digital pròpia del centre. }\end{array}$ \\
\hline $\begin{array}{l}\text { Centre educatiu } \\
\text { Comunitat } \\
\text { educativa i entorn }\end{array}$ & $\begin{array}{l}\text { 4. Comunicació, } \\
\text { difusió i transferència } \\
\text { del coneixement }\end{array}$ & $\begin{array}{l}\text { Utilitza eines digitals per } \\
\text { comunicar-se i compartir els } \\
\text { seus coneixements amb altres } \\
\text { docents. }\end{array}$ & $\begin{array}{l}\text { Gestiona recursos oberts } \\
\text { en xarxa per publicar les } \\
\text { seves experiències i } \\
\text { compartir-les. }\end{array}$ & $\begin{array}{l}\text { Forma docents, mitjançant } \\
\text { activitats reconegudes per } \\
\text { l'administració educativa, en } \\
\text { l'ús de les tecnologies digitals } \\
\text { per compartir i crear } \\
\text { coneixements. }\end{array}$ & $\begin{array}{l}\text { Serveix de referent en l'ús de recursos } \\
\text { tecnològics per difondre i compartir } \\
\text { el seu coneixement, transformant la } \\
\text { institució escolar en centre } \\
\text { d'innovació al servei de la comunitat. }\end{array}$ \\
\hline $\begin{array}{l}\text { Centre educatiu } \\
\text { Comunitat } \\
\text { educativa i entorn }\end{array}$ & $\begin{array}{l}\text { 5. Continguts digitals i } \\
\text { comunitat educativa }\end{array}$ & $\begin{array}{l}\text { Accedeix i comenta els } \\
\text { continguts distribuïts en } \\
\text { diferents espais digitals del } \\
\text { centre. }\end{array}$ & $\begin{array}{l}\text { Utilitza els espais digitals } \\
\text { del centre com a editor } \\
\text { d'algun d'ells amb } \\
\text { l'objectiu de compartir } \\
\text { coneixements i } \\
\text { experiències. }\end{array}$ & $\begin{array}{l}\text { Gestiona un espai digital propi } \\
\text { com a mitjà per publicar i } \\
\text { difondre el seu coneixement } \\
\text { professional i fer participar a la } \\
\text { comunitat educativa. }\end{array}$ & $\begin{array}{l}\text { Crea i gestiona espais virtuals per } \\
\text { difondre el coneixement collectiu i } \\
\text { per afavorir la comunicació i la } \\
\text { interacció entre els membres de la } \\
\text { comunitat educativa. }\end{array}$ \\
\hline
\end{tabular}


DIMENSIÓ 4. Personal i professional

\begin{tabular}{|c|c|c|c|c|c|}
\hline Àmbits & $\begin{array}{l}\text { Conceptes clau per a } \\
\text { la definició dels } \\
\text { indicadors }\end{array}$ & Nivell 1. Principiant & Nivell 2. Mitjà & Nivell 3. Expert & Nivell 4. Transformador \\
\hline $\begin{array}{l}\text { Centre educatiu } \\
\text { Comunitat educativa i } \\
\text { entorn }\end{array}$ & $\begin{array}{l}\text { 1. Accés lliure a la } \\
\text { nformació, creació i } \\
\text { difusió de material } \\
\text { didàctic amb llicències } \\
\text { bbertes }\end{array}$ & $\begin{array}{l}\text { Comparteix materials didàctics } \\
\text { reelaborats i distribuilts en obert a la } \\
\text { xarxa }\end{array}$ & $\begin{array}{l}\text { Elabora materials didàctics oberts i els } \\
\text { comparteix a la xarxa seguint un } \\
\text { estàndard que faciliti la cerca i } \\
\text { accessibilitat. }\end{array}$ & $\begin{array}{l}\text { Organitza, etiqueta i cataloga els recursos } \\
\text { educatius oberts (REO) per tipus, àrees i } \\
\text { etapes educatives en funció de les } \\
\text { necessitats de la comunitat educativa. }\end{array}$ & $\begin{array}{l}\text { Potencia l'ús de REO mitjançant la creació } \\
\text { i/o difusió de repositoris oberts de } \\
\text { materials didàctics. }\end{array}$ \\
\hline $\begin{array}{l}\text { Aula } \\
\text { Desenvolupament } \\
\text { professional }\end{array}$ & $\begin{array}{l}\text { 2. Lideratge en l'ús } \\
\text { de les tecnologies } \\
\text { digitals }\end{array}$ & $\begin{array}{l}\text { Utilitza les tecnologies digitals amb els } \\
\text { alumnes fent de referent pel que fa al } \\
\text { seu ús. }\end{array}$ & $\begin{array}{l}\text { Utilitza les tecnologies digitals, } \\
\text { integrant-les a la docència, i compartint } \\
\text { experiències amb els companys. }\end{array}$ & $\begin{array}{l}\text { Coordina l'ús de les tecnologies digitals a } \\
\text { nivell de centre. }\end{array}$ & $\begin{array}{l}\text { Assessora el centre en la utilització i } \\
\text { gestió de les tecnologies digitals i difon la } \\
\text { experiència i les bones pràctiques. }\end{array}$ \\
\hline $\begin{array}{l}\text { Centre educatiu } \\
\text { Comunitat educativa i } \\
\text { entorn }\end{array}$ & $\begin{array}{l}\text { 3. Participació i } \\
\text { col-laboració de la } \\
\text { comunitat educativa }\end{array}$ & $\begin{array}{l}\text { Participa dels recursos de centre com a } \\
\text { visitant, consultant informació i fent ús } \\
\text { dels espais comunicatius oberts a la } \\
\text { participació. }\end{array}$ & $\begin{array}{l}\text { Utilitza espais i recursos per promoure } \\
\text { la participació social i de la comunitat } \\
\text { educativa durant les activitats docents. }\end{array}$ & $\begin{array}{l}\text { Serveix de referent per a l'ús d'espais i } \\
\text { recursos digitals de centre promovent } \\
\text { activitats innovadores i compartint la seva } \\
\text { experiència. }\end{array}$ & $\begin{array}{l}\text { Gestiona i investiga sobre els espais i } \\
\text { tecnologies digitals del centre dirigits a la } \\
\text { participació de la comunitat educativa, } \\
\text { establint i proposant directrius orientades } \\
\text { a la innovació i millora. }\end{array}$ \\
\hline $\begin{array}{l}\text { Desenvolupament } \\
\text { professional }\end{array}$ & $\begin{array}{l}\text { 4. Identitat } \mathrm{i} \\
\text { presència digital }\end{array}$ & $\begin{array}{l}\text { Utilitza la identificació digital } \\
\text { professional en les comunicacions de } \\
\text { forma habitual i el seu perfil actualitzat } \\
\text { als espais virtuals del centre. }\end{array}$ & $\begin{array}{l}\text { Té un perfil digital i un currículum } \\
\text { professional actualitzat online. }\end{array}$ & $\begin{array}{l}\text { Utilitza les xarxes socials i professionals } \\
\text { com a mitjà de comunicació i interacció } \\
\text { professional. }\end{array}$ & $\begin{array}{l}\text { Utilitza les xarxes per al desenvolupament } \\
\text { professional, per promoure l' ús i } \\
\text { conscienciar de la importància als } \\
\text { membres de la comunitat. }\end{array}$ \\
\hline $\begin{array}{l}\text { Desenvolupament } \\
\text { professional }\end{array}$ & $\begin{array}{l}\text { 5. Entorn personal } \\
\text { d'aprenentatge (EPA) }\end{array}$ & $\begin{array}{l}\text { Utilitza diferents aplicacions } \\
\text { d'escriptori i web per gestionar els } \\
\text { continguts de l'aula i accedir a la } \\
\text { informació. }\end{array}$ & $\begin{array}{l}\text { Configura el seu EPA utilitzant eines } \\
\text { digitals per l'aprenentatge, fonts } \\
\text { d'informació i xarxa personal } \\
\text { d'aprenentatge. }\end{array}$ & $\begin{array}{l}\text { Col-labora amb els docents del centre en } \\
\text { la creació dels seus EPA. }\end{array}$ & $\begin{array}{l}\text { Assessora en l'ús dels EPA a la comunitat } \\
\text { educativa. }\end{array}$ \\
\hline $\begin{array}{l}\text { Comunitat educativa i } \\
\text { entorn } \\
\text { Desenvolupament } \\
\text { professional }\end{array}$ & $\begin{array}{l}\text { 6. Comunitats } \\
\text { d'aprenentatge virtuals: } \\
\text { formals, no formals i } \\
\text { informals }\end{array}$ & $\begin{array}{l}\text { Accedeix i utilitza materials docents } \\
\text { compartits en xarxa per a l'acció } \\
\text { docent a l'aula. }\end{array}$ & $\begin{array}{l}\text { Utilitza I'aprenentatge en xarxa com a } \\
\text { mitjà de formació permanent. }\end{array}$ & $\begin{array}{l}\text { Fomenta l'aprenentatge en xarxa entre els } \\
\text { membres de la comunitat educativa. }\end{array}$ & $\begin{array}{l}\text { Gestiona un ecosistema d'aprenentatge } \\
\text { entre els membres de la comunitat } \\
\text { educativa i altres institucions. }\end{array}$ \\
\hline $\begin{array}{l}\text { Desenvolupament } \\
\text { professional }\end{array}$ & $\begin{array}{l}\text { 7. Formació } \\
\text { permanent }\end{array}$ & $\begin{array}{l}\text { Realitza activitats de formació, } \\
\text { reconegudes per l'administració } \\
\text { educativa, relacionades amb les } \\
\text { tecnologies digitals. }\end{array}$ & $\begin{array}{l}\text { Es forma de manera permanent ("en } \\
\text { qualsevol lloc i qualsevol moment") } \\
\text { mitjançant activitats de formació } \\
\text { relacionades amb les tecnologies } \\
\text { digitals i reconegudes per } \\
\text { l'administració educativa. }\end{array}$ & $\begin{array}{l}\text { Transforma la seva pràctica docent, } \\
\text { mitjançant la incorporació de les } \\
\text { tecnologies digitals a aquesta, } \\
\text { incorporant els coneixements obtinguts } \\
\text { en les activitats de formació: } \\
\text { "transferència de la formació". }\end{array}$ & $\begin{array}{l}\text { Participa com a formador en activitats de } \\
\text { formació permanent del professorat } \\
\text { relacionades amb les tecnologies digitals. }\end{array}$ \\
\hline
\end{tabular}




\section{Referències}

Almås, A. G., \& Krumsvik, R. J. (2007). Digitally literate teachers in leading edge schools in norway. Journal of in-Service Education, 33(4), 479-497. DOI: http://dx.doi.org/10.1080/13674580701687864

Brynjolfsson, E. \& McAfee, A. (2014). The Second Machine Age: Work, Progress, and Prosperity in a Time of Brilliant Technologies. New York: Norton \& Company.

Castells, M. (2000) La era de la información. Vol. 1. La sociedad red. (2ª edición). Madrid: Alianza.

Castells, M. (2002). La dimensión cultural de Internet. Consultat el 5 de maig de 2015, des de http://www.uoc.edu/culturaxxi/esp/articles/castells0502/castells0502.html

Churches, A. (2007). Bloom's Digital Taxonomy. Consultat el 2 de març de 2015, des de http://www.eduteka.org/pdfdir/TaxonomiaBloomDigital.pdf

Comisión Europea (2012a). Informe conjunto de 2012 del Consejo y de la Comisión sobre la aplicación del marco estratégico para la cooperación europea en el ámbito de la educación y la formación (ET 2020). Consultat el 6 de març de 2015, des de: http://eur-lex.europa.eu/legal-

Comisión Europea. (2012b). Un nuevo concepto de educación: invertir en las competencias para lograr mejores resultados socioeconómicos. Dictamen del Comité Económico y Social Europeo sobre la Comunicación de la Comisión al Parlamento Europeo, al Consejo, al Comité Económico y Social Europeo y al Comité de las Regiones. Estrasburgo: Comisión Europea

Comisión Europea (2013a). Una nueva revolución industrial. Consultat el 16 de març de 2015, des de http://doi.org/10.2775/69805

Comisión Europea (2013b). Supporting teacher competence development. Consultat el 5 de març de 2015, des de http://ec.europa.eu/education/policy/school/doc/teachercomp_en.pdf

Comisión Europea (2013c). DIGCOMP: A Framework for Developing and Understanding Digital Competence in Europe. http://ftp.jrc.es/EURdoc/JRC83167.pdf

Delgado, J. M. \& Gutiérrez, J. (1999). Métodos y técnicas cualitativas de investigación en ciencias sociales. Madrid: Síntesis.

Enlaces (2011). Competencias y estándares TIC para la profesión docente. Centro de Educación y Tecnología (Enlaces). Ministerio de Educación, Gobierno de Chile.

EPICT (2006). European Pedagogical ICT Licence: Concept description: EContent. Consultat el 25 de març de 2015, des de http://www.epict.org/files/EPICTsyllabus.pdf

Esteve, F. (2015). La competencia digital docente (Doctoral dissertation). Consultat el 10 de maig, des de http://francescesteve.es/tesis/ 
Fraser, J., Atkins, L., \& Richard, H. (2013). DigiLit leicester. Supporting teachers, promoting digital literacy, transforming learning. Leicester City Council.

Generalitat de Catalunya (2009). Llei d'Educació de Catalunya 12/2009, del 10 de juliol. DOGC núm. 5422, de 16/07/2009.

Generalitat de Catalunya (2013b). Competències bàsiques de l'àmbit digital. Consultat el 2 de març de 2015, des de http://www20.gencat.cat/docs/Educacio/Home/Departament/Publicacions/Col_leccio ns/Competencies_basiques/competencies_digital_primaria.pdf

Generalitat de Catalunya (2015). Projecte interdepartamental de competència digital docent. ACORD GOV/157/2014. DOGC núm. 6759 - 27/11/2014.

Gisbert \& Esteve (2011). Digital Leaners: la competencia digital de los estudiantes universitarios. La Cuestión Universitaria, 7. 2011, pp. 48-59.

Gisbert, M. (coordinadora); Prats, M.A. \& Cabrera, N. (2015). Aprenentatge mòbil. Com incorporar els dispositius mòbils a l'aprenentatge? Informes Breus, 58. Fundació Jaume Bofill

Gisbert, M. \& Johnson, L. (2015). Educación y tecnología: nuevos escenarios de aprendizaje desde una visión transformadora. RUSC. Universities and Knowledge Society Journal, 12(2). págs. 1-14. doi http://dx.doi.org/10.7238/rusc.v12i2.2570

ISTE (2008). NETS•T for Teachers: National Educational Technology Standards for Teachers, Second Edition. EUA. Consultat el 10 de març de 2015, des de http://www.eduteka.org/pdfdir/EstandaresNETSDocentes2008.pdf

Katic, E. (2008). Preservice teachers conceptions about computers: an ongoing search for transformative appropriations of modern technologies. Teachers and Teaching, 14(2), 157-179. doi: http://dx.doi.org/10.1080/13540600801983344

Krueger, R. A. (1991): El grupo de discusión. Guía práctica para la investigación aplicada. Madrid: Pirámide.

Krugman, P. (2012). Robots y capitalistas sin escrúpulos. El País. Consultat el 10 de març de 2015, des de http://economia.elpais.com/economia/2012/12/14/actualidad/1355509963_633692.ht $\mathrm{ml}$

Larraz, V. (2013). La competència digital a la universitat. Tesi doctoral. Universitat d'Andorra. Identificador: TD-017-100006/201210.

Lázaro, J. L., Estebanell, M. \& Tedesco, J. C. (2015). Inclusión y cohesión social en una sociedad digital. RUSC. Universities and Knowledge Society Journal, 12(2). págs. 1-16. doi http://dx.doi.org/10.7238/rusc.v12i2.2459

Mertler, C. A. (2001). Designing scoring rubrics for your classroom. Practical Assessment, Research \& Evaluation, 7 (25), 1-10. 
Oblinger, D., \& Oblinger, J. L. (2005). Educating the net generation (Vol. 264). Educause Washington, DC.

OECD (2012). Education at a Glance 2012. OECD indicators. Consultat el 10 de març de 2015, des de http://www.oecd-ilibrary.org/education/education-at-a-glance2012_eag-2012-en

Pedró, F. (2009). New millennium learners in higher education: Evidence and policy implications. París: Centre for Educational Research and Innovation (CERI). OECD.

Prensky, M. (2001). Digital natives, digital immigrants. On the Horizon, 9(5). Consultat el 10 de març de 2015, des de http://dx.doi.org/10.1108/10748120110424816

Sánchez-Antolín, P., Ramos, F. J., \& Sánchez, J. (2014). Formación continua y competencia digital docente: el caso de la Comunidad de Madrid. Revista Iberoamericana de Educación, 65, 91-110.

Tejada, J. (2009). Competencias docentes. Profesorado: revista de currículum y formación del profesorado. Consultat el 8 d'abril de 2015, des de http://www.ugr.es/ recfpro/rev132COL2.pdf

Unión Europea (2006). Competencias clave para el aprendizaje permanente. Consultat el 10 de maig de 2015, des de http://www.mecd.gob.es/dctm/ministerio/educacion/mecu/movilidadeuropa/competenciasclave.pdf?documentId $=0901 \mathrm{e} 72 \mathrm{~b} 80685 \mathrm{fb} 1$

Unesco (2008). Estándares de competencia en TIC para docentes. Consultat el 10 de març de 2015, des de http://www.eduteka.org/EstandaresDocentesUnesco.php

Unesco (2009). Directrices sobre políticas de inclusión en la educación. Consultat el 10 de març de 2015, des de http://unesdoc.unesco.org/images/0017/001778/177849s.pdf Unesco (2011). Enfoques estratégicos sobre las TICs en educación en América Latina y el Caribe. Consultat el 10 de març de 2015, des de http://unesdoc.unesco.org/images/0022/002232/223251s.pdf

Unesco 2013. Informe de 2013/4. Enseñanza y aprendizaje: Lograr la calidad para todos. Consultat el 10 de març de 2015, des de http://unesdoc.unesco.org/images/0022/002261/226159s.pdf

Unión Europea (2014). Comprender la Políticas de la Unión Europea. Una nueva revolución industrial. Consultat el 5 de maig de 2015, des de http://europa.eu/pol/pdf/flipbook/es/enterprise_es.pdf

Van den Akker, J., Gravemeijer, K., McKenney, S., \& Nieveen, N. (Eds.). (2006). Educational design research. Routledge.

Wilson, C., Grizzle, A., Tuazon, R., Akyempong, K. \& Cheung, C. (2011). Alfabetización mediática e informacional. Currículum para profesores. París: UNESCO. Consultat el 4 d'abril de 2015, des de http://unesdoc.unesco.org/images/0021/002160/216099S.pdf 